\title{
Erratum to: Population attributable risks of modifiable reproductive factors for breast and ovarian cancers in Korea
}

\author{
Boyoung Park ${ }^{1,2}$, Sohee Park ${ }^{2,3}$, Hai-Rim Shin ${ }^{4}$, Aesun Shin ${ }^{1,5}$, Yohwan Yeo ${ }^{5}$, Ji-Yeob Choi ${ }^{6}$, Kyu-Won Jung ${ }^{2}$, \\ Byoung-Gie Kim ${ }^{7}$, Yong-Man Kim ${ }^{8}$, Dong-Young Noh ${ }^{9}$, Sei-Hyun Ahn ${ }^{10}$, Jae Weon Kim ${ }^{11}$, Sokbom Kang ${ }^{12}$, \\ Jae Hoon Kim ${ }^{13}$, Tae Jin Kim ${ }^{14}$, Daehee Kang ${ }^{5,6,15}$, Keun-Young Yoo ${ }^{5}$ and Sue K. Park ${ }^{5,6,15^{*}}$
}

\section{Erratum}

After publication of the original article [1], the authors noticed an error in the Acknowledgements section. One of the supporting grants is missing. The correct version of the Acknowledgements section is included below:

\begin{abstract}
Acknowledgements
The study is part of a systematic analysis of attributable causes of cancer in Korea conducted by working group experts in collaboration with the National Cancer Center, Korea and the International Agency for Research on Cancer. This study was supported by a research grant from the National Cancer Center, Korea (NCC-0710160) and grants from the National R\&D Program for Cancer Control, Ministry for Health, Welfare and Family affairs, Republic of Korea (1420190 and 0920010). We thank Mathieu Boniol from the International Prevention Research Institute, Lyon, France and Paolo Boffetta from the Tisch Cancer Institute, Mount Sinai School of Medicine, New York, United States of America for their help while they were working at the International Agency for Research on Cancer, Lyon, France.
\end{abstract}

\begin{abstract}
Author details
${ }^{1}$ Graduate School of Cancer Science and Policy, Goyang, Korea. ${ }^{2}$ National Cancer Control Institute, National Cancer Center, Goyang, Korea.

${ }^{3}$ Department of Epidemiology and Health Promotion, Graduate School of Public Health, Yonsei University, Seoul, Korea. ${ }^{4}$ Western Pacific Regional Office, World Health Organization, Manila, Philippines. ${ }^{5}$ Department of Preventive Medicine, Seoul National University College of Medicine, 103 Daehakro, Chongno-gu, Seoul 110-799, Korea. ${ }^{6}$ Department of Biomedical Science, Seoul National University Graduate School, Seoul, Korea. ${ }^{7}$ Department of Obstetrics and Gynecology, Samsung Medical Center \& Sungkyunkwan University School of Medicine, Seoul, Korea. ${ }^{8}$ Department of Obstetrics and Gynecology, University of Ulsan College of Medicine, Asan Medical Center, Seoul, Korea. ${ }^{9}$ Department of Surgery and Cancer Research Institute, Seoul National University College of Medicine, Seoul, Korea.

${ }^{10}$ Department of Surgery, University of Ulsan College of Medicine, Asan Medical Center, Seoul, Korea. "'Department of Obstetrics and Gynecology, Seoul National University Hospital and Seoul National University College of Medicine, Seoul, Korea. ${ }^{12}$ Department of Gynecologic Oncology, National Cancer Center, Goyang, Korea. ${ }^{13}$ Department of Obstetrics and Gynecology, Gangnam Severance Hospital, Yonsei University College of Medicine, Seoul,
\end{abstract}

\footnotetext{
*Correspondence: suepark@snu.ac.kr

${ }^{5}$ Department of Preventive Medicine, Seoul National University College of Medicine, 103 Daehakro, Chongno-gu, Seoul 110-799, Korea

${ }^{6}$ Department of Biomedical Science, Seoul National University Graduate School, Seoul, Korea
}

Korea. ${ }^{14}$ Department of Obstetrics and Gynecology, Cheil General Hospital and Women's Healthcare Center, Dankook University Medical College, Seoul, Korea. ${ }^{15}$ Cancer Research Institute, Seoul National University, Seoul, Korea.

Received: 24 February 2016 Accepted: 24 February 2016 Published: 4 March 2016

\section{Reference}

1. Park B, Park S, Shin HR, Shin A, Yohwan Y, Choi JY, et al. Population attributable risks of modifiable reproductive factors for breast and ovarian cancers in Korea. BMC Cancer. 2016;16:5. doi:10.1186/s12885-015-2040-0.
Submit your next manuscript to BioMed Central and we will help you at every step:

- We accept pre-submission inquiries

- Our selector tool helps you to find the most relevant journal

- We provide round the clock customer support

- Convenient online submission

- Thorough peer review

- Inclusion in PubMed and all major indexing services

- Maximum visibility for your research

Submit your manuscript at www.biomedcentral.com/submit
(C) 2016 Park et al. Open Access This article is distributed under the terms of the Creative Commons Attribution 4.0 International License (http://creativecommons.org/licenses/by/4.0/), which permits unrestricted use, distribution, and reproduction in any medium, provided you give appropriate credit to the original author(s) and the source, provide a link to the Creative Commons license, and indicate if changes were made. The Creative Commons Public Domain Dedication waiver (http://creativecommons.org/publicdomain/zero/1.0/) applies to the data made available in this article, unless otherwise stated. 